\title{
Remission in Children and Adolescents Diagnosed with Attention-Deficit/Hyperactivity Disorder via an Effective and Tolerable Titration Scheme for Osmotic Release Oral System Methylphenidate
}

\author{
Wen-Jiun Chou, M.D., Shin-Jaw Chen, M.D., ${ }^{2}$ Ying-Sheue Chen, M.D., ${ }^{3}$ Hsin-Yi Liang, M.D., ${ }^{4}$ \\ Chih-Chien Lin, M.D., ${ }^{5}$ Ching-Shu Tang, M.D., ${ }^{1}$ Yu-Shu Huang, M.D., ${ }^{4}$ Chin-Bin Yeh, M.D., ${ }^{6}$ \\ Miao-Chun Chou, M.D., ${ }^{1}$ Dai-Yueh Lin, M.D., ${ }^{3}$ Po-Hsun Hou, M.D., ${ }^{5}$ Yu-Yu Wu, M.D., ${ }^{4}$ Hung-Jen Liu, M.D., ${ }^{3}$ \\ Ya-Fen Huang, M.D., ${ }^{4}$ Kai-Ling Hwang, M.D., ${ }^{3}$ Chin-Hong Chan, M.D., ${ }^{5}$ Chia-Ho Pan, M.D., ${ }^{3}$ \\ Hsueh-Ling Chang, M.D., ${ }^{4}$ Chi-Fen Huang, M.D., ${ }^{4}$ and Ju-Wei Hsu, M.D. ${ }^{3}$
}

\begin{abstract}
Objectives: The purpose of this study was to identify the optimal dose of osmotic release oral system methylphenidate (OROS-MPH) using a dosage forced-titration scheme to achieve symptomatic remission in children with attention- deficit/ hyperactivity disorder (ADHD). We also evaluated the efficacy and safety of, and patient and parent satisfaction with, the change in therapy from immediate-release methylphenidate (IR-MPH) to OROS-MPH over 10 weeks.

Method: We recruited 521 children and adolescents aged 6-18 years with an American Psychiatric Association, Diagnostic and Statistical Manual of Mental Disorders, 4th ed. (DSM-IV) diagnosis of ADHD, who had received IR-MPH treatments $(<70 \mathrm{mg} /$ day) for at least 1 month. The treatment, switched from IR-MPH to OROS-MPH according to a conversion scheme, started with a 6-week forced-titration phase of OROS-MPH to achieve symptomatic remission (defined as a score of 0 or 1 for each of the first 18 ADHD items in the Chinese version of the Swanson, Nolan, and Pelham, Version IV [SNAP-IV]), followed by a 4-week maintenance phase. The global ADHD severity and drug side effects of the participants were evaluated. Parents completed the ratings scales for the ADHD-related symptoms. Patient and parent satisfaction for the OROS-MPH treatment was also assessed. Results: Among the 439 participants with ADHD who completed the trial, 290 participants (66.1\%) achieved symptomatic remission. The mean dose of OROS-MPH among participants in remission was $36.7 \mathrm{mg}(1.08 \mathrm{mg} / \mathrm{kg})$ per day. Increased efficacy, superior satisfaction, and safety equivalent to that of IR-MPH were demonstrated in intra-individual comparisons from the baseline to the end of study. Determinants for remission included less severe ADHD symptoms (SNAP-IV score $<40$ ), no family history of ADHD, and an appropriate dosage of medication according to the patient's weight.

Conclusions: The findings suggest remission as a treatment goal for ADHD therapy by providing an optimal dosage of medication for children and adolescents with ADHD through using an effective and tolerable forced-titration scheme.
\end{abstract}

\section{Introduction}

A TTENTION-DEFICIT/HYPERACTIVITY DISORDER (ADHD), characterized by inattention, hyperactivity, and impulsivity, significantly affects children's behavior and performance at school and home (American Academy of Pediatrics 2000), and also disrupts their relationships with family, teachers, and peers in the absence of appropriate management (Mannuzza et al. 1997). Longterm studies following pediatric patients with ADHD into adolescence and adulthood have shown its long-term impacts on their

\footnotetext{
${ }^{1}$ Department of Child Psychiatry, Chang Gung Memorial Hospital, Kaohsiung Medical Center, Chang Gung University College of Medicine, Kaohsiung, Taiwan.

${ }^{2}$ Dr. Yin's Clinic, Tainan, Taiwan.

${ }^{3}$ Department of Psychiatry, Taipei Veterans General Hospital, National Yang-Ming University, Taipei, Taiwan.

${ }^{4}$ Department of Child Psychiatry, Chang Gung Memorial Hospital - Linkou Medical Center, Chang Gung University College of Medicine, Tao-Yuang, Taiwan.

${ }^{5}$ Department of Psychiatry, Taichung Veterans General Hospital, Taichung, Taiwan.

${ }^{6}$ Department of Psychiatry, Tri-Service General Hospital, Taipei, Taiwan.

This work was supported by Jansessen-Cilag, Taipei, Taiwan (Protocol ID: CCT-TWN-MA4). The consent and assent forms, study protocol, and any advertisements for participants were approved by the Joint Institute Review Board, Taipei, Taiwan (JIRB: 06-056-P). The Clinical Trials of government Identifier of the protocol Registration System was NCT00518232.
} 
academic achievement, social functioning, self-esteem, occupational function, and employment stability (Weiss et al. 1985; Barkley et al. 1990). The long-term outcomes are problematic (Satterfield and Schell 1997; Barkley et al. 2006) and often complicated by comorbid conditions (Biederman et al. 1995; Fischer et al. 2002). Some ADHD patients do reach symptomatic remission (15-33\% with few or no symptoms) (Weiss et al. 1985; Barkley et al. 1990; Biederman et al. 1996) or functional remission (20\%) in long-term follow-up studies (Biederman et al. 1998). Therefore, the major goals of therapy are not only to improve the symptoms but also to restore optimal functionality in the emotional, behavioral, academic, and social realms (Steele et al. 2006a).

Historically, "response to treatment" was used as the target or primary outcome of effectiveness in the treatment of psychiatric disorders, including ADHD (Swanson et al. 2001; Hechtman et al. 2004; Remschmidt 2005). The majority of studies on ADHD indicate that $>50 \%$ of patients responded to various medical treatments at clinically effective doses (American Academy of Pediatrics 2001; Pelham et al. 2001; Kutcher et al. 2004). Central nervous system (CNS) stimulants, in particular, have a very high response rate in the treatment of ADHD (Wilens and Spencer 2000; Gau et al. 2006, 2007). A 25-30\% reduction in total symptom scores was observed using rating scales, or a "mild to moderate improvement" was observed using clinical global rating (Spencer et al. 2001). Some studies have suggested different definitions or criteria for response by using different rating scales (Conners 1997; Stein et al. 2003; Kelsey et al. 2004; Steele et al. 2006). Because the severity of the baseline illness is not considered, a significant number of "responders" may still continuously have prominent symptoms and have functional impairment (Spencer et al. 2001; Kemner et al. 2005). Therefore, the concept of response and remission was first introduced for the treatment of major depressive disorder (MDD) in the early 1990s (Frank et al. 1991; Kupfer 1991). Remission is clearly defined as an asymptomatic state, and at least a $50 \%$ reduction in symptoms as defined using a standard rating scale, or with the clinical global impression that the patient is minimally or not at all ill (Kemner et al. 2005; Wigal et al. 2005). The consensus guidelines for MDD from Europe, Canada, and the United States recommend that the goal of therapy should include the remission of symptoms and a return to the premorbid level of social and occupational function (Anderson et al. 2000; Canadian Psychiatric Association Network for Mood and Anxiety Treatments 2001; Lam and Kennedy 2004). This approach has also gained acceptance in the treatment of bipolar disorder, anxiety disorder, and schizophrenia, with only slight variation of the consensus guidelines (Andreasen et al. 2005). The goal for the treatment of ADHD should also be upgraded. That the goal of the standard treatment should be to achieve remission rather than only response has been strongly emphasized (Steele et al. 2006a; Ramos-Quiroga and Casas 2011), as ADHD patients in remission will have an improved chance of attaining functional recovery and wellness (Canadian Psychiatric Association Network for Mood and Anxiety Treatments 2001; Andreasen et al. 2005). Therefore, it is proposed that clinical research in ADHD should use "remission" as the primary outcome (Steele et al. 2006a).

Over the past few years, a number of different definitions of remission in ADHD have been used in clinical trials. The various definitions of ADHD remission share a standardized symptom scale with a defined cutoff score indicating that the patient has lost diagnostic status, the symptoms have decreased to the level of minimal or no symptoms, as well as that the patient is functioning optimally or with minimal, if any, impairment in function (Swan- son et al. 2001; Steele et al. 2006a; Gau et al. 2008a). Therefore, there are two aspects of remission: A symptomatic remission and a functional remission. The most commonly used scales for ADHD are the Swanson, Nolan and Pelham-Fourth Edition scale (SNAP-IV) (Swan 1995), the ADHD Rating Scale, Version-IV (ADHD-RS-IV) (Stein et al. 2003), the Clinical Global Impressions ADHD-Improvement scale (CGI-ADHD-I), and the Clinical Global Impressions - ADHD-Severity scale (CGI-ADHD-S) to assess the response to treatment or remission (Stein et al. 2003; Kelsey et al. 2004). Remission is defined as a mean total score of $\leq 1$ on most of the standardized rating scales as mentioned previously in symptom aspect, and/or $\leq 2$ on the CGI-ADHD-S scale to indicate not at all ill or borderline existence of ADHD symptoms (Stein et al. 2003; Swanson et al. 2003 ; Kelsey et al. 2001; Kemner et al. 2005; Wigal et al. 2005; Steele et al. 2006a). Some studies use total score of $\leq 18$ on the ADHD-RS-IV as the definition of remission (Stein et al. 2003; Dickson et al. 2011). These definitions set realistic goals for achieving specific end points and guide the clinician toward maximizing the outcome of the treatment.

Patients can become virtually asymptomatic and even achieve remission of ADHD with appropriate management (Swanson et al. 2001; Kelsey et al. 2004). Failure to achieve remission is associated with a significant impact on the patient's psychosocial functioning, and an increase in the risk of relapse and a chronic course (Satterfield and Schell 1997; Biederman et al. 1998). Management of ADHD should consider those medication strategies that have been demonstrated to increase the probability of reaching remission (Steele et al. 2006b; Gau et al. 2008a; Chou et al. 2009). Methylphenidate is the best-studied stimulant for ADHD, and a number of studies demonstrate that the remission rates range from $21-56 \%$ in ADHD patients treated with immediate-release methylphenidate (IR-MPH) (Greenhill et al. 2006; Swanson et al. 2001), to 44-62\% in ADHD children and adolescents treated with osmotic release oral system methylphenidate (OROS-MPH) (Swan 1995; Swanson et al. 2004; Steele et al. 2006b; Gau et al. 2008a). There is no report concerning the remission of amphetamine in patients with ADHD so far in spite of amphetamine having been used in treatment of ADHD for years. Among children and adolescents with ADHD who are treated with atomoxetine, $27-30 \%$ of them achieve remission between weeks 4 and 8 (Michelson et al. 2002; Kelsey et al. 2004; Dickson et al. 2011), and the remission rate has been observed to gradually increase up to $59 \%$ at week 12 (Dickson et al. 2011).

The prevalence of ADHD in Taiwan had been reported to be $\sim 9.9 \%$ among primary school children, with a 3 to 1 predominance in the boys (Wang et al 1993). Similar to the results in Western countries, the efficacy and safety of IR-MPH and OROS-MPH have been established in two clinical trials conducted in ethnic Chinese ADHD populations (Yang et al 2004; Gau et al 2006). In addition, after switching to OROS-MPH from IR-MPH, the improvement in remission rates of ADHD, behaviors, and school performance through improving patients' drug adherence have been demonstrated in two multisite studies conducted among Chinese ADHD populations in Taiwan (Gau et al, 2008a; Chou et al, 2009).

Although many studies provide strong evidence that children and adolescents with ADHD are good responders to MPH, > 30\% of them are poor responders or are unable to reach remission under treatment with either IR-MPH or OROS-MPH (Swanson et al. 2001; Mohammadi and Akhondzadeh 2007). Several factors have been suggested as influencing the rate of achieving remission, including subtype of ADHD, existence of psychiatric comorbidities, adherence to medication, behavioral intervention, and kinds or 
dosages of medications (Steele et al. 2006b; Ramos-Quiroga and Casas 2011). That remission rates for ADHD symptoms increase with higher doses of OROS-MPH has been demonstrated (Stein et al. 2003; Newcorn et al. 2010). The significant relationship between higher doses of medication and improved rates of remission suggests that the treatment of ADHD should include strategies to identify an optimal or adequate dosage to maximize the benefit of treatment (Steele et al. 2006b).

In order to achieve the treatment goal of remission via a dosage forced-titration scheme, we conducted an open-label prospective observation study that included a large sample size from multiple sites. The aims of this study were 1) to investigate the ADHD remission rate in clinical settings based on standardized criteria of remission with OROS-MPH while employing an intensive dosage forced-titration scheme; 2) to assess the optimal dosage to achieve remission, efficacy, safety profiles, and patient and parent satisfaction for OROS-MPH treatment; and 3) to identify factors contributing to the remission of ADHD symptoms.

\section{Method}

\section{Study design and participants}

This 10-week noncomparative observational study was conducted at the outpatient clinics of six hospitals in northern, central, and southern Taiwan by 20 experienced board-certificated child psychiatrists, and was approved by each site's institutional review board in accordance with the ethical principles outlined in the Declaration of Helsinki and good clinical practice. It was designed to identify patients with ADHD who were currently being treated with IR-MPH b.i.d. or t.i.d. and were switching to OROS-MPH under consideration of adherence, and to investigate the final dosage of OROS-MPH to achieve remission for participants. It began in September 2006 and was completed in June 2007.

Inclusion criteria were: Age 6-19 years; clinical diagnosis of ADHD based on the relevant American Psychiatric Association, Diagnostic and Statistical Manual of Mental Disorders, 4th ed. (DSM-IV) diagnostic criteria and standardized clinical assessments, as determined by experienced board-certificated child psychiatrists; treatment with IR-MPH $(<70 \mathrm{mg} /$ day $)$ for at least 1 month; IR-MPH treatment during the preceding month without severe adverse events or possible contraindications; and, with participants'/parents' written informed consent. Exclusion criteria were: Any systematic disease or clinically significant gastrointestinal problem; and, comorbid psychiatric disorders, except for conduct disorder and oppositional defiant disorder (ODD).

\section{Study procedure}

The study consisted of a 6-week forced-titration phase of OROSMPH to achieve remission, and a 4-week maintenance period. In the first baseline visit, the participants and parents were interviewed by the investigators to obtain information with respect to demographics, clinical MPH treatment, and family history related to ADHD. Without a washout period, the participants were immediately switched to OROS-MPH once daily in the early morning according to their IR-MPH dosage, under consideration of adherence. Participants receiving an IR-MPH dosage $<15 \mathrm{mg}$, between 15 and $30 \mathrm{mg}$, and $>30 \mathrm{mg}$ per day were converted to 18,36 , and $54 \mathrm{mg}$ once daily OROS-MPH, respectively (Swanson et al. 2004). Dosage adjustment was conducted at biweekly intervals (visits 2 and 3). During the 6-week forced-titration phase, the dose for those participants who did not achieve the criteria for "remission" or “optimal response" (Kupfer 1991; Kemner et al. 2005; Findling et al. 2008) was increased to the next dose level (36 mg/day, then $54 \mathrm{mg}$ /day). The maximum dose of OROS-MPH per day was $54 \mathrm{mg}$, as this was the maximal daily dose approved in Taiwan. The dose was decreased if clinically intolerable adverse events emerged. The final titration dose of OROS-MPH at week 6 was maintained for the subsequent 4 weeks until the last monthly visit to the clinic (visits 4 to 5 ).

The investigators completed the CGI-ADHD-I and the CGIADHD-S scales. Meanwhile, parents/caregivers completed the Chinese version of the SNAP-IV scale and the Barkley Side Effect Rating Scale (Barkley SERS) at each visit. The participants' and parents' satisfaction with the OROS-MPH treatment were also assessed.

\section{Measures}

Dosage record and adherence measurement. The dosage information was recorded on a case-report-form (CRF) for the titration pattern and the maintenance dose. It included the start and stop dates of treatment and any reasons for the premature discontinuation of the drug and/or nonadherence. Drug adherence was assessed by investigators based on the reports of participants and their parents, and pill counting at each visit. The number of remaining doses for each treatment was entered in the adherence section of the CRF. Poor adherence was defined as missing one or more doses on a school day on two or more days per week.

Efficacy assessments. The key instrument used to determine the effectiveness outcome was the Chinese version of SNAPIV that consisted of 18 ADHD items and 8 ODD items. Each item was scored for severity on a four-point Likert scale (0-3: $0=$ not at all to 3 = very much) (Swan 1995; Gau et al. 2008b).

Definition of symptomatic remission. Symptomatic remission was defined as a score of 0 or 1 on each of the first 18 ADHD items on the SNAP-IV scale; and was equated to a low symptom severity (not at all or just a slightly ill, referred to as SNAP-IV-18) (Swan 1995; Swanson et al. 2004; Steele et al. 2006a; Gau et al. 2008a).

Physician-rated CGI-ADHD-S. A single-item rating based on the experience of the psychiatrists for the severity in ADHD symptoms and is rated on a seven-point scale (1-7: $1=$ not ill to $7=$ extremely severe). Lower scores indicate a reduced severity of ADHD (Stein et al. 2003; Kelsey et al. 2004; Gau et al. 2008a).

Physician-rated CGI-ADHD-I. A single-item rating based on the impression of the psychiatrists for the improvement in ADHD symptoms is rated on a seven-point scale $(1-7,1=$ very much improved to $7=$ very much worse) (Kelsey et al. 2004; Gau et al. 2008a).

Patient and parent report of satisfaction with ADHD treatment. Treatment was rated based on the patients' and parents' reports regarding their satisfaction with the medication on a five-point scale (1-5: $1=$ completely dissatisfied, to $5=$ completely satisfied).

Safety assessment. Safety assessments consisted of monitoring and recording all side effects, adverse events, vital signs, physical examination findings, and body weight. All parents completed the Barkley SERS that consisted of 17 items, rated from 0 (absent) to 9 (serious), to measure the side effects. An adverse 
event was any undesirable sign, symptom, or medical condition occurring after starting the therapy and was reported by investigators. Medical conditions/diseases present before the treatment was started were only considered as adverse events if they worsened during the treatment.

\section{Statistical analysis}

The data from all hospitals that participated in this protocol were combined. All data from the intent-to-treat (ITT) patients who received the medication were considered eligible for analysis. Data were summarized with respect to the demographic and baseline characteristics, efficacy, and safety observations and measurements. Descriptive statistics were performed to identify the optimal dosage of OROS-MPH for the different strata of the patients' weight at the end of the treatment. The effectiveness of OROS$\mathrm{MPH}$ therapy in this patient population by last observation carried forward (LOCF) was explored using the Chinese version of SNAPIV, CGI-ADHD-S, CGI-ADHD-I, and the global assessment of satisfaction. Analyses are presented as summary statistics and $95 \%$ confidence intervals (CI) for all participants and subgroups. The Mantel-Haenszel $\chi^{2}$ test was used to analyze the category data. Paired $t$ test was used to test the intra-individual comparison from the baseline to each visit within the same participants. The assessment of safety was mainly based on the frequency of adverse events and the Barkley SERS. The pre-selected $\alpha$ level was set at $p<0.05$.

Results

\section{Sample description}

Of the 521 children and adolescents with ADHD recruited into the first phase, $439(86.6 \%)$ participants completed the 10-week trial. The study cohort and the reasons for the withdrawals are summarized in the patient flow diagram (Fig. 1). For the 521 par- ticipants with ADHD, the mean age was 10.4 years, ranging from 7 to 17 years, with a significant predominantly male versus female ratio of 8:1. The distributions of the ADHD combined type, inattentive type, and hyperactive/impulsivetype, were $65.6 \%, 31.3 \%$, and $3.1 \%$ respectively. Forty-two $(8.1 \%)$ participants had a comorbid illness. Prior to participation in the trial, the mean dose of IR-MPH had been $21.5 \mathrm{mg} /$ day, ranging from 5 to $65 \mathrm{mg} /$ day. The mean duration of IR-MPH treatment was 8.7 months. Eighty-two (15.7\%) participants withdrew from the study throughout the 10week study period. All the other 439 participants and their parents/ guardians completed each of the six assessments without any missing data. The reasons for withdrawal over the 10-week study period included consent withdrawal (5\%), lost to follow-up (3.3\%), adverse reactions from OROS-MPH (5\%), and unsatisfactory therapeutic effects of OROS-MPH $(2.1 \%)$. To compare the differences between the completion and withdrawal groups, the withdrawal from the study was found to be significantly related to younger age, lower body weight and height, lower IR-MPH dosage prior to participating in the trial, and poor adherence with study medication (Table 1).

\section{Remission rate and mean daily dosage of OROS-MPH}

At the baseline, $>50 \%$ of the participants with ADHD receiving IR-MPH were underdosed based on the observation of their lacking clinical response, and the symptomatic remission rate of IR-MPH was only $4.8 \%$, according to the definition of the study (score $\leq 1$ on each item of the first 18 items of SNAP-IV). Using the forcedtitration of OROS-MPH dosage to increase the dosage during the first 6 weeks, the remission rate significantly increased with time from $4.8 \%$ (at baseline), $25 \%$ (week 2), $44.2 \%$ (week 4), $58.8 \%$ (week 6), up to $59.6 \%$ (week 10) among 507 ITT participants. Among 439 participants who completed the 10-week follow-up assessments, $290(66.1 \%)$ achieved symptomatic remission $(95 \%$ CI, 61.6-70.5\%). The mean total daily dose of OROS-MPH (mean

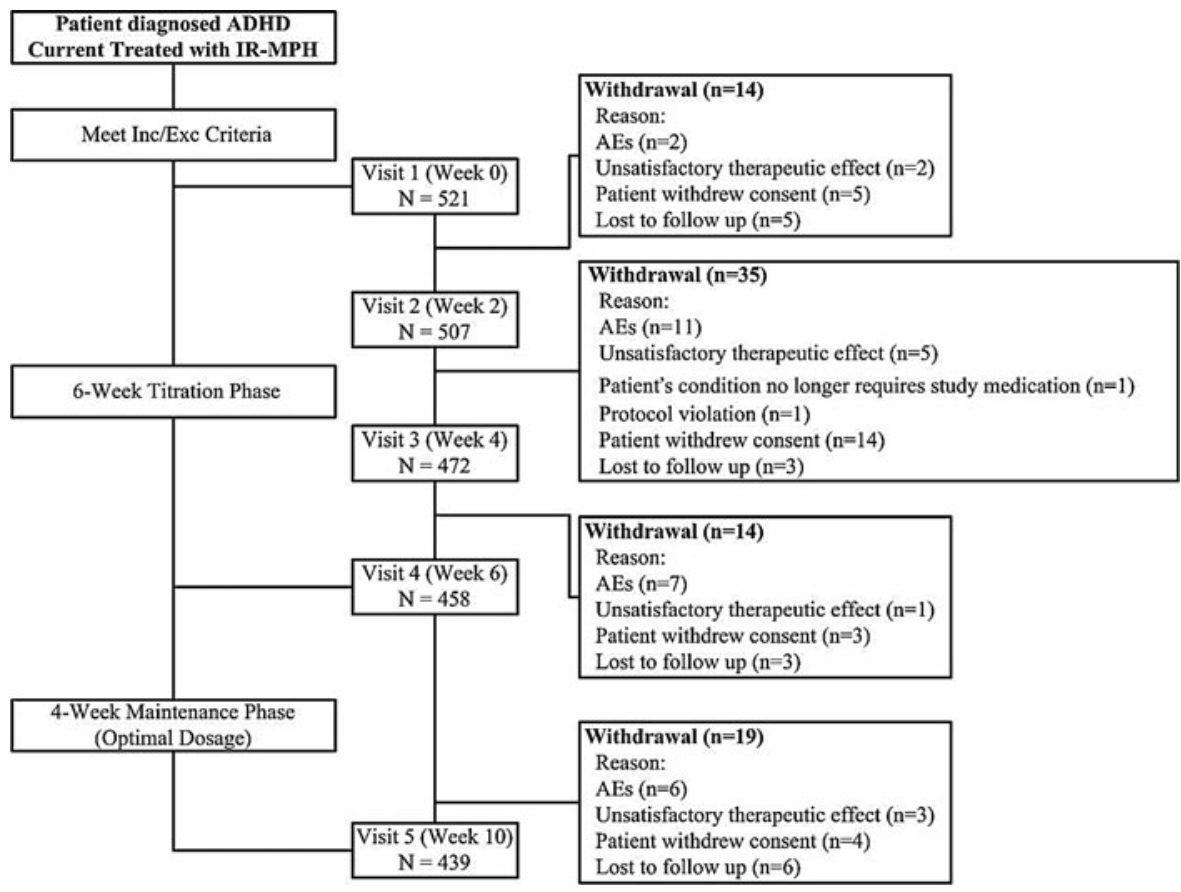

FIG. 1. Overview of patient flow diagram. AEs=adverse events; $A D H D=$ attention-deficit/hyperactivity disorder; IR-MPH= immediate-release methylphenidate. 
Table 1. Demographic and Baseline Characteristics of Study Participants

\begin{tabular}{|c|c|c|c|c|}
\hline Characteristics & $\begin{array}{c}\text { All enrolled }(\mathrm{n}=521) \\
\mathrm{n}(\%)\end{array}$ & $\begin{array}{c}\text { Completion }(\mathrm{n}=439) \\
\mathrm{n}(\%)\end{array}$ & $\begin{array}{c}\text { Withdrawal }(\mathrm{n}=82) \\
\mathrm{n}(\%)\end{array}$ & Group differences \\
\hline Male, $n(\%)$ & $461(88.5)$ & $387(88.2)$ & $74(90.2)$ & $\begin{aligned} \chi^{2} & =0.295 \\
p & =0.586\end{aligned}$ \\
\hline Age, mean (SD) & $10.4(2.2)$ & $10.5(2.2)$ & $9.7(2.2)$ & $\begin{aligned} t & =3.099 \\
p & =0.002 *\end{aligned}$ \\
\hline Weight, mean (SD) & $36.8(13.2)$ & $37.6(13.6)$ & $32.9(10.4)$ & $\begin{aligned} t & =2.943 \\
p & =0.003 *\end{aligned}$ \\
\hline Height, mean (SD) & $139.4(14.2)$ & $140.3(14.3)$ & $134.7(12.8)$ & $\begin{aligned} t & =3.291 \\
p & =0.001 *\end{aligned}$ \\
\hline \multicolumn{5}{|l|}{ Education, $n(\%)$} \\
\hline Kindergarten & $3(0.6)$ & $3(0.7)$ & $0(0.0)$ & \multirow{4}{*}{$\begin{aligned} \chi^{2} & =1.964 \\
p & =0.161\end{aligned}$} \\
\hline Elementary & $440(84.5)$ & $365(83.1)$ & $75(91.5)$ & \\
\hline Junior high & $72(13.8)$ & $66(15.0)$ & $6(7.3)$ & \\
\hline Senior high & $6(1.2)$ & $5(1.1)$ & $1(1.2)$ & \\
\hline IR-MPH Dose, mean (SD) & $21.5(10.3)$ & $22.2(10.60)$ & $18.2(8.15)$ & \multirow{4}{*}{$\begin{aligned} t & =3.168 \\
p & =0.001 * \\
\chi^{2} & =9.379 \\
p & =0.002 *\end{aligned}$} \\
\hline $15 \mathrm{mg}$ & $173(33.2)$ & $136(31.0)$ & $37(45.1)$ & \\
\hline $15 \mathrm{mg}-30 \mathrm{mg}$ & $209(40.1)$ & $176(40.1)$ & $33(40.2)$ & \\
\hline $30 \mathrm{mg}$ & $139(26.7)$ & $127(28.9)$ & $12(14.6)$ & \\
\hline Duration (months), mean (SD) & $8.7(13.5)$ & $8.9(13.9)$ & $7.3(11.1)$ & $\begin{aligned} t & =0.993 \\
p & =0.321\end{aligned}$ \\
\hline \multicolumn{5}{|l|}{ DSM-IV ADHD subtype } \\
\hline Inattentive & $163(31.3)$ & $141(32.1)$ & $22(26.8)$ & \multirow{3}{*}{$\begin{aligned} \chi^{2} & =0.791 \\
p & =0.373\end{aligned}$} \\
\hline Combined & $342(65.6)$ & $13(3.0)$ & $57(69.5)$ & \\
\hline Hyperactive-impulsive & $16(3.1)$ & $285(64.9)$ & $3(3.7)$ & \\
\hline \multicolumn{5}{|l|}{ Concomitant drug } \\
\hline Clonidine & $3(0.6)$ & $2(0.5)$ & $1(1.2)$ & \multirow{2}{*}{$\begin{aligned} \chi^{2} & =0.703 \\
p & =0.401 \\
\chi^{2} & =0.374 \\
p & =0.540\end{aligned}$} \\
\hline Antipsychotics & $2(0.4)$ & $2(0.5)$ & $0(0.0)$ & \\
\hline \multicolumn{5}{|l|}{ Cormorbid disorder } \\
\hline ODD & $23(4.4)$ & $17(3.9)$ & $6(7.3)$ & \multirow{3}{*}{$\begin{aligned} \chi^{2} & =1.939 \\
p & =0.163 \\
\chi^{2} & =0.187 \\
p & =0.665 \\
\chi^{2} & =3.476 \\
p & =0.062\end{aligned}$} \\
\hline Anxiety disorder & $1(0.2)$ & $1(0.2)$ & $0(0.0)$ & \\
\hline Other disorder & $18(3.5)$ & $18(4.1)$ & $0(0.0)$ & \\
\hline \multicolumn{5}{|l|}{ Adherence } \\
\hline Good adherence & $511(98.08)$ & $439(100.0)$ & $72(87.8)$ & \multirow{2}{*}{$\begin{array}{l}\chi^{2}=54.447 \\
p=0.0001 *\end{array}$} \\
\hline Poor adherence & $10(1.92)$ & $0(0.0)$ & $10(12.2)$ & \\
\hline
\end{tabular}

$\mathrm{SD}=$ standard deviation; $\mathrm{ADHD}=$ attention-deficit/hyperactivity disorder; $\mathrm{IR}-\mathrm{MPH}=$ immediate-release methylphenidate; $\mathrm{DSM}-\mathrm{IV}=\mathrm{American}$ Psychiatric Association, Diagnostic and Statistical Manual of Mental Disorders, 4th ed.; ODD = oppositional defiant disorder.

Statistic: Mantel-Haenszel $\chi^{2}$ for category data and $t$ value for continuous data between completion and withdrawal subjects.

$* p<0.005$.

daily weight-dose per visit) was increased from $22.2 \mathrm{mg}(0.69 \mathrm{mg} / \mathrm{kg}$, visit 1), $24.4 \mathrm{mg}(0.99 \mathrm{mg} / \mathrm{kg}$, visit 2), $34.4 \mathrm{mg}$ (1.07 mg/kg, visit 3), $37.8 \mathrm{mg}(1.10 \mathrm{mg} / \mathrm{kg}$, visit 4$)$, to $37.9 \mathrm{mg}(1.11 \mathrm{mg} / \mathrm{kg}$, visit 5$) . \mathrm{In}$ both the remission and non-remission groups, the mean total daily dose of OROS-MPH increased significantly $(p<0.001)$ by each visit in comparison with baseline. The non-remission group had higher mean daily doses than did the remission group from visit 2 to the end of study. At the end of the study, the mean daily dose of OROS-MPH reached $36.7 \mathrm{mg}, 1.08 \mathrm{mg} / \mathrm{kg}$ in the remission group and $40.3 \mathrm{mg}, 1.17 \mathrm{mg} / \mathrm{kg}$ in non-remission group ( $p=0.005$ ) (Fig. 2).

\section{Determinants for remission based on the body-weight dose at the end of the study}

From the previous study in Taiwan, the general dose-body weight conversion scheme of IR-MPH was $0.8-1.2 \mathrm{mg} / \mathrm{kg}$ per day (Gau et al. 2008a). Therefore, we divided the 521 participants into three subgroups according to the dose-body weight as $<0.8,0.8$ to $<1.3$, and $\geq 1.3 \mathrm{mg} / \mathrm{kg}$. The distribution of the body weight OROS-MPH doses $<0.8,0.8$ to $<1.3$, and $\geq 1.3 \mathrm{mg} / \mathrm{kg}$ at the end of the study was $147(28.2 \%), 218(41.8 \%)$, and $156(30.0 \%)$, respectively. The remission rates at the end of the study in each dosage group were $52.4 \%(n=77), 65.1 \%(n=142)$, and $53.2 \%$ $(n=83)$ respectively. Table 2 summarizes the odds ratios (OR) and $95 \% \mathrm{CI}$ for the variables of the OROS-MPH body-weight dose that were significantly related to the final remission rate $(<0.8 \mathrm{mg} / \mathrm{kg}$ was used as the reference group). The most predictive OROS-MPH body-weight dose for remission was 0.8 to $<1.3 \mathrm{mg} / \mathrm{kg}$ among the ITT population (OR, 1.70; CI, 1.11-2.60; $p=0.015$ ).

\section{Changes in efficacy and satisfaction}

Among the 439 participants who completed the treatment, there was a significant decrease in the total score and three sub-scores of 


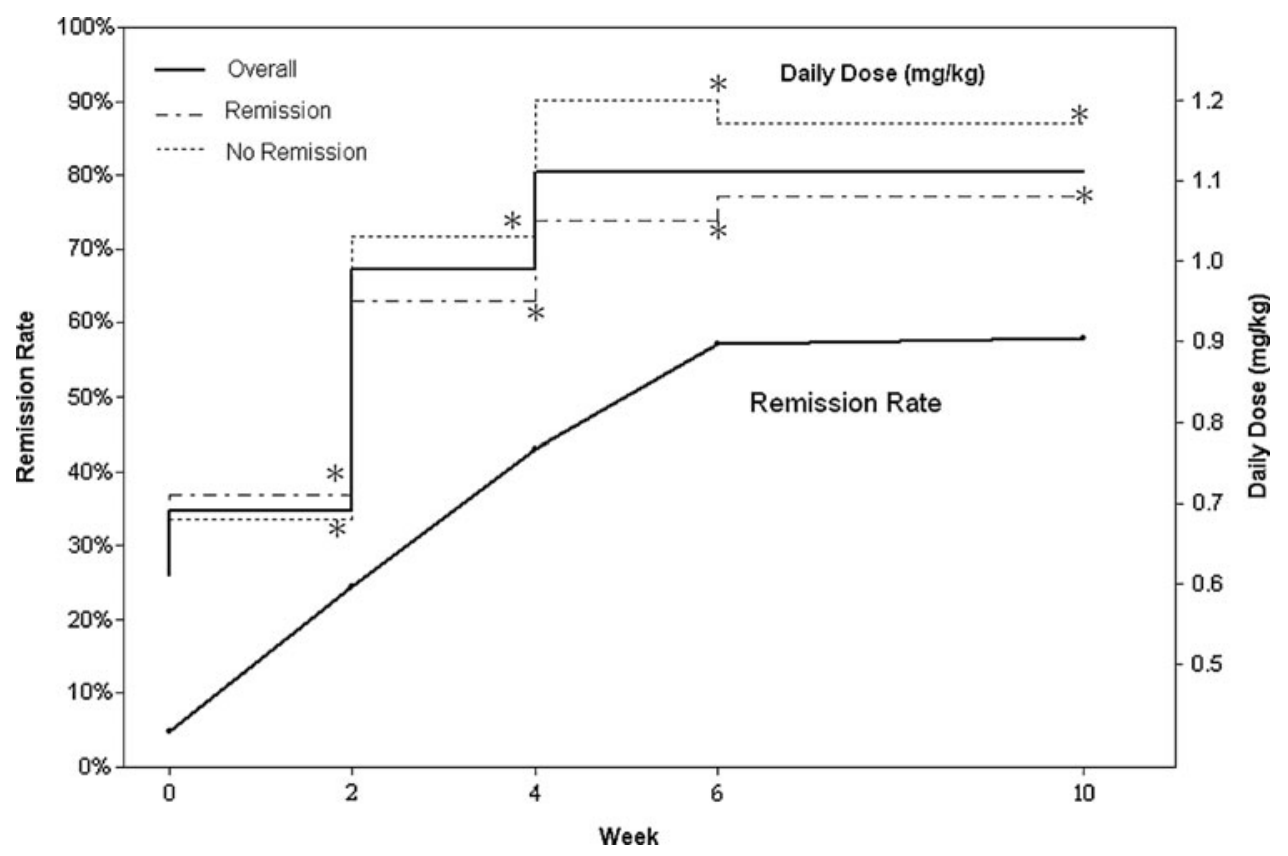

FIG. 2. Plot of optimal response rate with the average osmotic release oral system methylphenidate (OROS-MPH) dosage. Paired $t$ test $p$-value: Comparison of the change between baseline and each visit within the same subjects. $*=p<0.0001$.

the Chinese SNAP-IV $(p<0.001)$, CGI-ADHD-S $(p<0.001)$, and CGI-ADHD-I $(p<0.001)$ as intra-individual comparison from the baseline to each visit throughout the study period. The intraindividual comparison of patient and parent global satisfaction to treatment within the same participants improved significantly from visit 3 to the end of the study $(p<0.001)$ (Fig. 3 ).

\section{Safety after forced-titration of OROS-MPH}

Among the items of the Barkley SERS, poor appetite was the only one exacerbated on visit 3 , but improved on later visits. The other side effects gradually decreased in intensity throughout the whole study period and the difference from baseline reached statistical significance from visit 3 to the end of the study (Table 3 ).

At the end of study, there was a slight decrease in both mean body weight $(-0.85 \mathrm{~kg})$ and mean respiratory rate $(-0.44 / \mathrm{min})$, and

Table 2. Remission Rate at the End of the Study Based on the Body-Weight Dose

\begin{tabular}{lccc}
\hline & \multicolumn{3}{c}{ OROS-MPH dose (mg/kg/day) } \\
\cline { 2 - 4 } & \multicolumn{3}{c}{$0.8 \sim$} \\
& $<0.8 \mathrm{mg} / \mathrm{kg}$ & $<1.3 \mathrm{mg} / \mathrm{kg}$ & $\geq 1.3 \mathrm{mg} / \mathrm{kg}$ \\
\hline $\begin{array}{l}\text { ITT population } \\
\quad(n=521)\end{array}$ & $147(28.2 \%)$ & $218(41.8 \%)$ & $156(30.0 \%)$ \\
No. of remission & 77 & 142 & 83 \\
Remission rate & $52.4 \%$ & $65.1 \%$ & $53.2 \%$ \\
OR & & 1.70 & 1.03 \\
$(95 \%$ CI $)$ & & $(1.11-2.60)$ & $(0.66-1.62)$ \\
$p$ - value & & $0.015^{\mathrm{a}}$ & 0.886 \\
\hline
\end{tabular}

OROS-MPH $=$ osmotic release oral system methylphenidate; ITT = intent to treat; $\mathrm{OR}=$ odds ratio; $\mathrm{CI}=$ confidence interval.

${ }^{\text {a }}$ Wald $\chi^{2}$ based on logistic model and dose group $<0.8 \mathrm{mg} / \mathrm{kg}$ taken as the reference group.

$p<0.05$. a slight increase in mean pulse rate $(+5.09 \mathrm{bpm})$ in comparison with baseline with statistical significance $(p<0.001)$. The other vital signs, including height and blood pressure (systolic and diastolic), remained stable throughout the study period.

Only $5 \%$ of the participants withdrew from the study because of side effects, and these participants mostly left because of poor appetite and insomnia. Any adverse event that was deemed by the investigator to be "probably" or "possibly" related to OROS$\mathrm{MPH}$, and that occurred in $\geq 3 \%$ of the participants at any time during the study period, was reported. The most frequently reported adverse events were decreased appetite (36.3\%), insomnia (20.0\%), and dry mouth (11.3\%). Three participants experienced at least one serious adverse event (two with pneumonia, and the other with abdominal pain, constipation, and an upper respiratory tract infection) that was not OROS-MPH-related.

\section{Discussion}

The results showed that $66 \%$ of participants treated with OROSMPH reached remission if the patient could tolerate the 6-week dosage forced-titration and the 4-week maintenance period with a maximal daily dose up to $54 \mathrm{mg}$. Our remission rate after shifting to OROS-MPH was very similar to the results (44-66\%) from randomized clinical trials with OROS-MPH in Western countries (Stein et al 2003; Steele et al. 2006). It indicated that the symptomatic remission instead of "response to treatment" of ADHD in our study was achievable among two thirds of patients treated with OROS-MPH, and that remission was a realistic and pragmatic goal.

Dosage is important in the treatment of ADHD with medications that have a greater remission rate at higher doses (Stein et al 2003; Swanson et al 2004). Underdosing is quite common in the medication for patients with ADHD; patients may exhibit response to the low dosage but they seldom reach remission in the current therapeutic settings (Weiss et al. 1985; Barkley et al. 1990; Satterfield et al. 2002; Barkley et al. 2006; Gau et al. 2008a). Our study showed that at the baseline, the mean IR-MPH daily dose after at 
A

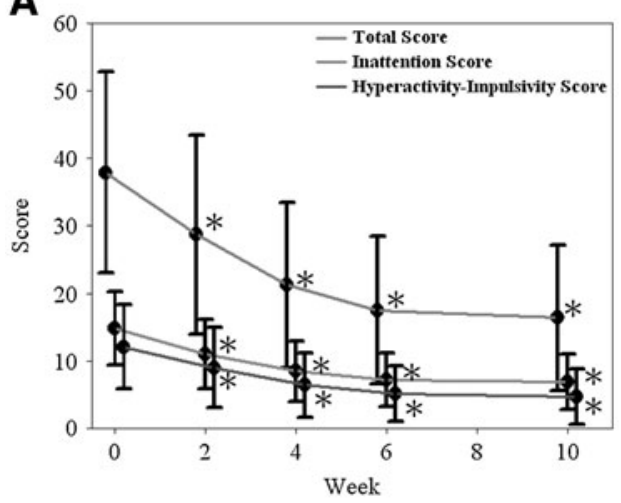

C

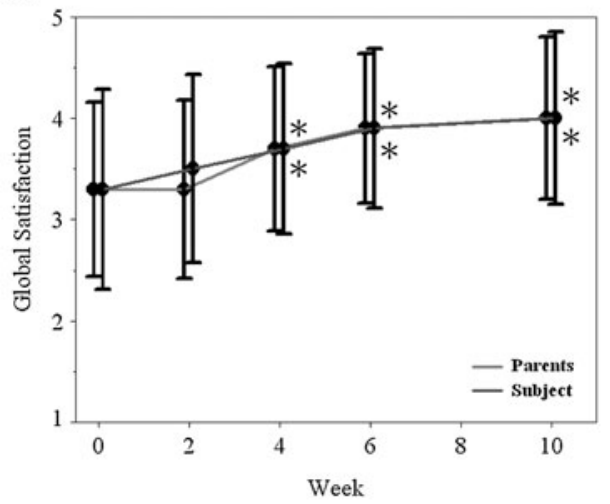

B

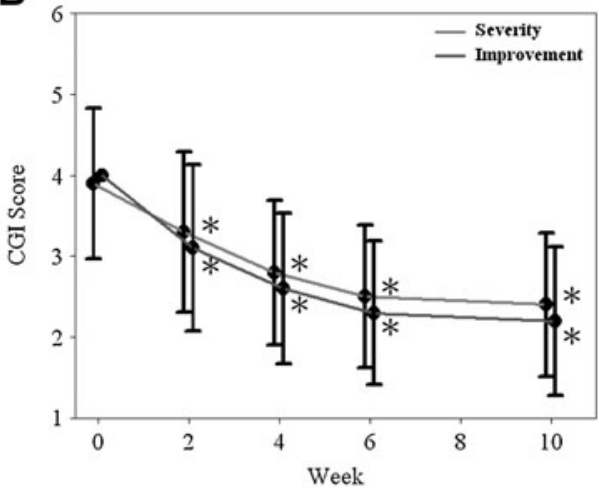

FIG. 3. Improvement on the (A) Swanson, Nolan, and Pelham, Version IV (SNAP-IV), (B) Clinical Global Impressions - ADHDSeverity scale (CGI-ADHD-S), and Clinical Global Impressions - ADHD-Improvement scale (CGI-ADHD-I) and (C) global satisfaction of subjects and parents in children with attention- deficit/hyperactivity disorder (ADHD) switched to osmotic release oral system methylphenidate (OROS-MPH) under force-titration $(n=439)$. Paired $t$ test $p$-value: Comparison of the change from baseline with each visit within the same subjects. $*=p<0.0001$.

Table 3. Differences of the Barkley Side Effects Measured Between Baseline and Visit 3 , as Well as Between Baseline and End Point

\begin{tabular}{|c|c|c|c|c|c|c|c|c|}
\hline & \multicolumn{2}{|c|}{$\mathrm{n}=439$} & & & \multicolumn{2}{|c|}{$\mathrm{n}=439$} & & \\
\hline & \multicolumn{2}{|c|}{ Visit 3-Baseline } & & & \multicolumn{2}{|c|}{ Endpoint-Baseline } & & \\
\hline & \multirow{2}{*}{$\begin{array}{c}\text { Baseline } \\
(\mathrm{n}=521) \\
\text { Mean } \pm S D\end{array}$} & \multirow{2}{*}{$\begin{array}{c}\text { Visit } 3 \\
(\mathrm{n}=472) \\
\text { Mean } \pm S D\end{array}$} & \multicolumn{2}{|c|}{ Group difference } & \multirow{2}{*}{$\begin{array}{c}\text { Baseline } \\
(\mathrm{n}=521) \\
\text { Mean } \pm S D\end{array}$} & \multirow{2}{*}{$\begin{array}{c}\text { Endpoint } \\
(\mathrm{n}=439) \\
\text { Mean } \pm S D\end{array}$} & \multicolumn{2}{|c|}{ Group difference } \\
\hline & & & t value & $\mathrm{p}$ value & & & $\mathrm{t}$ value & $\mathrm{p}$ value \\
\hline \multicolumn{9}{|l|}{ Barkley side effects } \\
\hline Poor appetite & $2.74 \pm 2.81$ & $2.75 \pm 2.65$ & 0.05 & 0.961 & $2.74 \pm 2.81$ & $2.67 \pm 2.66$ & -0.49 & 0.623 \\
\hline Trouble sleeping & $1.86 \pm 2.49$ & $1.72 \pm 2.36$ & -1.22 & 0.225 & $1.86 \pm 2.49$ & $1.41 \pm 2.16^{\mathrm{c}}$ & -3.83 & 0.001 \\
\hline Stomach aches & $0.54 \pm 1.50$ & $0.38 \pm 1.27^{\mathrm{a}}$ & -2.24 & 0.026 & $0.54 \pm 1.50$ & $0.23 \pm 0.94^{\mathrm{d}}$ & -5.01 & $<0.001$ \\
\hline Headaches & $0.82 \pm 1.58$ & $0.41 \pm 1.10^{\mathrm{d}}$ & -6.02 & $<0.001$ & $0.82 \pm 1.58$ & $0.28 \pm 0.99^{\mathrm{d}}$ & -7.32 & $<0.001$ \\
\hline Nightmares & $0.76 \pm 1.55$ & $0.42 \pm 1.15^{\mathrm{d}}$ & -4.74 & $<0.001$ & $0.76 \pm 1.55$ & $0.30 \pm 1.01^{\mathrm{d}}$ & -5.74 & $<0.001$ \\
\hline Daydreams & $1.40 \pm 2.18$ & $0.64 \pm 1.40^{\mathrm{d}}$ & -7.92 & $<0.001$ & $1.40 \pm 2.18$ & $0.48 \pm 1.25^{\mathrm{d}}$ & -9.67 & $<0.001$ \\
\hline Reduced communication & $0.99 \pm 1.85$ & $0.66 \pm 1.33^{\mathrm{d}}$ & -3.59 & $<0.001$ & $0.99 \pm 1.85$ & $0.50 \pm 1.21^{\mathrm{d}}$ & -5.03 & $<0.001$ \\
\hline Uninterested in others & $1.28 \pm 2.17$ & $0.72 \pm 1.34^{\mathrm{d}}$ & -5.40 & $<0.001$ & $1.28 \pm 2.17$ & $0.52 \pm 1.23^{\mathrm{d}}$ & -6.74 & $<0.001$ \\
\hline Shock & $0.62 \pm 1.46$ & $0.34 \pm 1.10^{\mathrm{d}}$ & -4.17 & $<0.001$ & $0.62 \pm 1.46$ & $0.28 \pm 0.97^{\mathrm{d}}$ & -5.27 & $<0.001$ \\
\hline Dry mouth & $1.56 \pm 2.28$ & $1.10 \pm 1.94^{\mathrm{d}}$ & -4.59 & $<0.001$ & $1.56 \pm 2.28$ & $0.73 \pm 1.60^{\mathrm{d}}$ & -8.00 & $<0.001$ \\
\hline Sentimental & $1.31 \pm 2.17$ & $0.82 \pm 1.62^{\mathrm{d}}$ & -4.98 & $<0.001$ & $1.31 \pm 2.17$ & $0.60 \pm 1.42^{\mathrm{d}}$ & -6.99 & $<0.001$ \\
\hline Anxiety & $1.39 \pm 2.23$ & $0.84 \pm 1.67^{\mathrm{d}}$ & -5.66 & $<0.001$ & $1.39 \pm 2.23$ & $0.60 \pm 1.47^{\mathrm{d}}$ & -7.35 & $<0.001$ \\
\hline Biting fingernails & $2.08 \pm 3.09$ & $1.17 \pm 2.27^{\mathrm{d}}$ & -8.76 & $<0.001$ & $2.08 \pm 3.09$ & $0.90 \pm 1.97^{\mathrm{d}}$ & -10.04 & $<0.001$ \\
\hline Unusually happy & $1.05 \pm 2.11$ & $0.57 \pm 1.47^{\mathrm{d}}$ & -5.23 & $<0.001$ & $1.05 \pm 2.11$ & $0.33 \pm 1.14^{\mathrm{d}}$ & -8.18 & $<0.001$ \\
\hline Drowsiness & $0.77 \pm 1.77$ & $0.52 \pm 1.37^{\mathrm{b}}$ & -2.92 & 0.004 & $0.77 \pm 1.77$ & $0.36 \pm 1.25^{\mathrm{d}}$ & -4.73 & $<0.001$ \\
\hline Tics/nervous movement & $0.45 \pm 1.40$ & $0.29 \pm 1.01^{\mathrm{b}}$ & -2.66 & 0.008 & $0.45 \pm 1.40$ & $0.25 \pm 1.04^{\mathrm{b}}$ & -2.96 & 0.003 \\
\hline
\end{tabular}

${ }^{\mathrm{a}} p<0.05 ;{ }^{\mathrm{b}} p<0.01 ;{ }^{\mathrm{c}} p=0.001 ;{ }^{\mathrm{d}} p<0.001$ by the paired $t$ test $\mathrm{SD}=$ standard deviation. 
least 1 month of treatment was only $21.4 \mathrm{mg}(0.61 \mathrm{mg} / \mathrm{kg})$ and the remission rate at the baseline prior to the switch to OROS-MPH was only $4.9 \%$. This finding suggests that even with the use of rating scales, child psychiatrists tend to use relatively low doses of drugs, such as IR-MPH twice a day, because of their concern about side effects and the patient's intolerance of medications, even though the patients still exhibit symptoms (Chou et al. 2009). Therefore, we can see that the clinical practice in Taiwan is relatively conservative, in which drugs given to ADHD children and adolescents are initially prescribed at a low level and are slowly titrated. As a result, the patients and parents question the efficacy of the medication. The subsequently poor drug adherence can cause a low remission rate, and the long-term treatment outcome will become equivocal. Therefore, to identify the optimal pharmacologic treatment for ADHD that quickly achieves and maintains remission, an initial titration and ongoing medication management are essential (MTA Cooperative Group 1999).

Forced-titration has been used in clinical trials of medication in child and adolescent patients with psychiatric disorders to evaluate the dose-response relationship (Stein et al. 2003; Findling et al. 2008; Schimmelmann et al. 2007). We applied the "forced-titration" method in order to attain complete remission over a short period in our study. This was also the first study to use this kind of scheme to challenge the dosage used in Eastern countries. As there is no consensus on the linear relationship between body weight and the optimal dose, there is no clear rationale or titration scheme to titrate the dosage of drugs (Stein et al. 2003). The initial conversion dosage for the IR and OROS formulations of MPH used in our study was: $\leq 15 \mathrm{mg}=18 \mathrm{mg}, 15-30 \mathrm{mg}=36 \mathrm{mg},>30 \mathrm{mg}=54 \mathrm{mg}$, respectively. These were very similar to those previously reported: $5 \mathrm{mg}$ t.i.d. $=18 \mathrm{mg}, 10 \mathrm{mg}$ t.i.d. $=36 \mathrm{mg}$, and $15 \mathrm{mg}$ t.i.d. $=54 \mathrm{mg}$ (Swanson et al. 2004). Participants were forced to the next dosage if they failed to reach symptomatic remission. The definition of remission used in our study was similar to those used in other clinical trials (Swanson et al. 2001, Steele et al. 2006a).

During the course of the forced-titration of OROS-MPH, adjusted by visit of study, the mean daily doses of OROS-MPH from visit 2 to the end of study increased from 0.69 to $1.11 \mathrm{mg} / \mathrm{kg}$ and resulted in the higher rate of remission from $25.9 \%$ to $66.1 \%$. In our study, it was an acceptable and reasonable average mean dose of IR-MPH, compared with a previous dosage survey in the Taiwan ethnic Chinese population in which the average treatment dose of IR-MPH was $26.7 \mathrm{mg}$ per day for 5-18-year-old patients and the general dose-body weight conversion scheme of IR-MPH was 0.8 $1.2 \mathrm{mg} / \mathrm{kg}$ per day (Gau et al. 2008a). Actually, the final dosage played an important role in the response to treatment and the improvement in ADHD patients (Stein et al. 2003). Patients receiving higher doses of medication and closer follow-up from their physicians in the medication arm of the trial had a higher remission rate in a Multimodal Treatment Study of Children with ADHD (MTA) study too (MTA Cooperative Group 1999; Swanson et al. 2001). In many randomized clinical trials, the remission rates range from 40 to $66 \%$ with OROS-MPH QD (Stein et al. 2003; Kelsey et al. 2004) and from 38 to $56 \%$ with IR-MPH TID (MTA Cooperative Group 1999; Swanson et al. 2001). In our study, the remission rates were significantly higher with OROS-MPH compared with IR-MPH ( $66.1 \%$ vs. $2.4 \%$, respectively). More than $50 \%$ of our patients achieved remission with this particular study design; therefore, our study demonstrated that titration of the dosage should be based on clinical evaluations and judgment coming from not only the clinical manifestations but also the psychometric evaluations of the severity of the symptoms, efficacy, tolerability, and functional improve- ments. For most children and adolescents, a careful initial titration could yield an effective maintenance dose; however, this does not prevent the need for a subsequent period of maintenance adjustment (MTA Cooperative Group 2004).

Because the titration period in this study was only 6 weeks, it might have shortened the time and opportunity to achieve remission. There were still $34 \%$ of patients who did not achieve remission. Compared to the multicenter Canadian studies of OROS-MPH, the remission rates were significantly higher with OROS-MPH than with IR-MPH ( $44 \%$ vs. $16 \%$, respectively; $p<0.001$ ) (Steele et al. 2005a,b, 2006b). The findings suggest that strategies with the highest chances of remission should be used early to maximize the benefits of therapy (Steele et al. 2006a). As we observed in our study, the probability of remission was increased by reaching an OROS-MPH body-weight dose between 0.8 and $1.3 \mathrm{mg} / \mathrm{kg}$. Therefore, to maximize the chance of achieving symptomatic remission with MPH in our study, adequate doses were required as early as possible.

Improved efficacy, better global satisfaction with the treatment, and similar side-effect profiles were demonstrated in the intraindividual comparisons of the subsequently increased dosage of OROS-MPH with the initial dosage of IR-MPH. Before the study began, most child psychiatrists expressed concern regarding the probability of a high dropout rate caused by the presence of side effects under such a forced-titration scheme. However, poor appetite was the only persistent concern, resulting in a slightly decreased body weight. Although a slightly increased pulse rate and respiratory rate were noted, the vital signs of patients were stable throughout the 10 -week study period. The withdrawal rate for the study was $15.7 \%$, and withdrawal because of adverse reactions to OROS-MPH was only 5\%. Patients with a younger age, lower weight and height, and lower IR-MPH dosage at baseline tended to withdraw from this study. As the participants were already receiving IR-MPH treatment ( $<70 \mathrm{mg}$ daily), they were tolerant to ADHD medicine, which may have been why our dropout rate was low compared with that in a previous study (Steele et al. 2006b).

OROS-MPH is the second-choice medication for ADHD patients if they have a poor response to the initial IR-MPH treatment, according to the health insurance regulations in Taiwan. Our study design and results partially reflect the real world practice and have clinical implications for the treatment strategy of ADHD in Taiwan.

\section{Limitations}

Relative to analogous investigations, the strengths of this study for setting MPH treatment goals to achieve remission include: It used the largest sample population of children and adolescents with ADHD examined to date; participants were recruited from a number of hospitals across northern, central, and southern Taiwan, and it was not a relatively confined clinical trial; and the comprehensiveness of the assessments for the status and determinants of remission, as well as for the side effects, satisfaction profiles, and ADHD symptoms.

Nonetheless, in interpreting the results of this study, several limitations should be considered. First, this was an open-label study; therefore, it was not possible to determine the level of response to placebo or effects of observer bias to the rating scales, which may have overestimated the effectiveness of the therapy. Second, there were no data concerning patients/parents who refused to participate in the study during the recruiting stage. According to the investigators' statement, the major reason for their 
refusal was that they were unable to fit in the study visit schedule, as well as they were satisfied with the effectiveness of IR-MPH prior to being recruited. Therefore, it is more likely that children with poor adherence or poor response to IR-MPH will be recruited into the study at baseline, and this will possibly decrease the remission rate. Third, there were only two opportunities (weeks 2 and 4) to adjust the dosage of OROS-MPH to achieve remission in our forced-titration scheme. Some participants might require a longer time to tolerate the side effects from the rapidly increased dosage of OROS-MPH during the titration phase. For these participants, we had to slow down the speed of titration and were unable to move forcefully to the higher dosage necessary for remission within 6 weeks. Fourth, there were only three dosing preparations of OROS$\mathrm{MPH}-18,36$, and $54 \mathrm{mg}$ - in this study, and the designed maximal daily dose was $54 \mathrm{mg}$. Some participants might need the dose $>54 \mathrm{mg}$ daily to achieve remission. If the titration period was prolonged and higher dosages were allowed, then we could expect that more participants would achieve remission, especially the adolescent cases. Finally, the observation data at school was lacking, as we did not have access to teachers' reports and parental work. In addition, there were no further assessments of functional outcome, because of the short duration of this study.

\section{Conclusions}

The majority $(59.6 \%)$ of 507 ITT participants, or $66 \%$ of 439 participants who completed the study, achieved symptomatic remission of ADHD with a forced-titration scheme of OROS-MPH with the maximal daily dose of $54 \mathrm{mg}$ within 6 weeks and 4 weeks maintenance. Symptomatic remission was defined as a score of 0 or 1 on each of the first 18 ADHD items on the SNAP-IV scale in this study. The mean dose of OROS-MPH among participants in achieving remission was $1.08 \mathrm{mg} / \mathrm{kg} /$ day, which was the optimal dosage in this study. Increased efficacy, superior satisfaction, and equivalent safety of OROS-MPH were demonstrated at the end of study, compared with IR-MPH.

\section{Clinical Significance}

The results of this 10-week, open-label, multisite study of child and adolescent patients with ADHD indicated that remission was a realistic and achievable target in treating ADHD with OROS-MPH and forcedtitration increase of dosage. Moreover, even with a once-daily administration of MPH, clinicians may need to adjust the dosage according to the effectiveness, the psychometric results from rating scales, and the associated side effects. Despite the limitations discussed earlier, the results of this analysis suggest that the forced-titration of OROS-MPH could help $>50 \%$ of ADHD patients to achieve remission with acceptable tolerability. However, $>30 \%$ of participants were unable to achieve remission finally, because some participants need a higher dosage than $54 \mathrm{mg}$, or need a slow titration to reduce side effects. Further studies are required to investigate the outcomes over a longer study period, and the relationship between higher doses and the maintenance of remission and functional recovery.

\section{Acknowledgment}

The authors acknowledge Susan Shur-Fen Gau for permission to use the Chinese version of the SNAP-IV scale.

\section{Disclosures}

W.-J. Chou, Y.-S. Huang, M.-C. Chou, C.-S. Tang, and Y.-Y. Wu have conducted clinical trials on behalf of Eli \& Lilly Co.,
Taiwan. Y.-S. Huang has also conducted clinical trials on behalf of Janssen-Cilag, Taiwan. W.-J. Chou, S.-J. Chen, Y.-Y. Wu, Y.-S. Huang, Y.-S. Chen, H.-Y. Liang, C.-B. Yeh, H.-L. Chang, and Y. -F. Huang are speakers and consultants for Jansessen-Cilag, Taiwan. H.-Y. Liang, C.-C. Lin, D.-Y. Lin, P.-H. Hou, H.-J. Liu, K.-L. Hwong, C.-H. Chan, C.H. Pan, C.-F. Huang, and J.-W. Hsu have no conflict of interests or financial ties to be disclosed. This work was supported by Jansessen-Cilag, Taiwan (Protocol ID: CCT-TWNMA4).

\section{References}

American Academy of Pediatrics. Clinical practice guideline: Diagnosis and evaluation of the child with attention-deficit/hyperactivity disorder. Pediatrics 105:1158-1170, 2000.

American Academy of Pediatrics. Clinical practice guideline: Treatment of the school-aged child with attention-deficit/hyperactivity disorder. Pediatrics 108:1033-1044, 2001.

Anderson IM, Nutt DJ, Deakin JF: Evidence-based guidelines for treating depressive disorders with antidepressants: A revision of the 1993 British Association for Psychopharmacology guidelines. J Psychopharmacol 14:3-20, 2000.

Andreasen NC, Carpenter WT Jr, Kane JM, Lasser RA, Marder SR, Weinberger DR: Remission in schizophrenia: Proposed criteria and rationale for consensus. Am J Psychiatry 162:441-449, 2005.

Barkley RA, Fischer M, Edelbrock C, Smallish L: The adolescent outcome of hyperactive children diagnosed by research criteria: I. An 8-year prospective follow-up study. J Am Acad Child Adolesc Psychiatry 29:546-557, 1990.

Barkley RA, Fischer M, Smallish L, Fletcher K: Young adult outcome of hyperactive children: Adaptive functioning in major life activities. J Am Acad Child Adolesc Psychiatry 45:192-202, 2006.

Biederman J, Faraone S, Milberger S, Curtis S, Chen L, Marrs A, Ouellette C, Moore P, Spencer T: Predictors of persistence and remission of ADHD into adolescence: Results from a four-year prospective follow-up study. J Am Acad Child Adolesc Psychiatry 35:343-351, 1996.

Biederman J, Mick E, Faraone SV: Normalized functioning in youths with persistent attention-deficit/hyperactivity disorder. J Pediatr 133:544-551, 1998.

Biederman J, Wilens T, Mick E, Milberger S, Spencer TJ, Faraone SV: Psychoactive substance use disorders in adults with attention deficit hyperactivity disorder (ADHD): Effects of ADHD and psychiatric comorbidity. Am J Psychiatry 152:1652-1658, 1995.

Canadian Psychiatric Association Network for Mood and Anxiety Treatments: Clinical guidelines for the treatment of depressive disorders. Can J Psychiatry 46:5S-90S, 2001.

Chou WJ, Chou MC, Tzang RF, Hsu YC, Gau SS, Chen SJ, Wu YY, Huang YF, Liang HY, Cheng H: Better efficacy for the osmotic release oral system methylphenidate among poor adherents to immediate-release methylphenidate in the three ADHD subtypes. Psychiatry Clin Neurosci 63:167-175, 2009.

Conners C: Connners' Rating Scale-Revised. North Tonawanda, NY: Multi-Health Systems; 1997.

Dickson RA, Maki E, Gibbins C, Gutkin SW, Turgay A, Weiss MD: Time courses of improvement and symptom remission in children treated with atomoxetine for attention-deficit/hyperactivity disorder: Analysis of Canadian open-label studies. Child Adolesc Psychiatry Ment Health 5:14, 2011.

Findling RL, Kauffman RE, Sallee FR, Carson WH, Nyilas M, Mallikaarjun S, Shoaf SE, Forbes RA, Boulton DW, Pikalov A: Tolerability and pharmacokinetics of aripiprazole in children and adolescents with psychiatric disorders: An open-label, doseescalation study. J Clin Psychopharmacol 28:441-446, 2008. 
Fischer M, Barkley RA, Smallish L, Fletcher K: Young adult followup of hyperactive children: self-reported psychiatric disorders, comorbidity, and the role of childhood conduct problems and teen CD. J Abnorm Child Psychol 30:463-475, 2002.

Frank E, Prien RF, Jarrett RB, Keller MB, Kupfer DJ, Lavori PW, Rush AJ, Weissman MM: Conceptualization and rationale for consensus definitions of terms in major depressive disorder: Remission, recovery, relapse, and recurrence. Arch Gen Psychiatry 48:851-855, 1991.

Gau SS, Chen SJ, Chou WJ, Cheng H, Tang CS, Chang HL, Tzang RF, Wu YY, Huang YF, Chou MC, Liang HY, Hsu YC, Lu HH, Huang YS: National survey of adherence, efficacy, and side effects of methylphenidate in children with attention-deficit/hyperactivity disorder in Taiwan. J Clin Psychiatry 69:131-140, 2008a.

Gau SS, Huang YS, Soong WT, Chou MC, Chou WJ, Shang CY, Tseng WL, Allen AJ, Lee P: A randomized, double-blind, placebocontrolled clinical trial on once-daily atomoxetine in Taiwanese children and adolescents with attention-deficit/hyperactivity disorder. J Child Adolesc Psychopharmacol 17:447-460, 2007.

Gau SS, Shang CY, Liu SK, Lin CH, Swanson JM, Liu YC, Tu CL: Psychometric properties of the Chinese version of the Swanson, Nolan, and Pelham, version IV scale - parent form. Int J Methods Psychiatr Res 17:35-44, 2008b.

Gau SS, Shen HY, Soong WT, Gau CS: An open-label, randomized, active-controlled equivalent trial of osmotic release oral system methylphenidate in children with attention-deficit/hyperactivity disorder in Taiwan. J Child Adolesc Psychopharmacol 16:441-455, 2006.

Greenhill L, Kollins S, Abikoff H, McCracken J, Riddle M, Swanson J, McGough J, Wigal S, Wigal T, Vitiello B, Skrobata A, Posner K, Ghuman J, Cunningham C, Davies M, Chuang S, Cooper T: Efficacy and safety of immediate-release methylphenidate treatment for preschoolers with ADHD. J Am Acad Child Adolesc Psychiatry 45:1284-1293, 2006.

Hechtman L, Abikoff H, Klein RG, Weiss G, Respitz C, Kouri J, Blum C, Greenfield B, Etcovitch J, Fleiss K, Pollack S: Academic achievement and emotional status of children with ADHD treated with long-term methylphenidate and multimodal psychosocial treatment. J Am Acad Child Adolesc Psychiatry 43:812-819, 2004.

Kelsey DK, Sumner CR, Casat CD, Coury DL, Quintana H, Saylor KE, Sutton VK, Gonzales J, Malcolm SK, Schuh KJ, Allen AJ: Once-daily atomoxetine treatment for children with attentiondeficit/hyperactivity disorder, including an assessment of evening and morning behavior: A double-blind, placebo-controlled trial. Pediatrics 114:e1-8, 2004.

Kemner JE, Starr HL, Ciccone PE, Hooper-Wood CG, Crockett RS: Outcomes of OROS methylphenidate compared with atomoxetine in children with ADHD: A multicenter, randomized prospective study. Adv Ther 22:498-512, 2005.

Kupfer DJ: Long-term treatment of depression. J Clin Psychiatry. 52(Suppl): 28-34, 1991.

Kutcher S, Aman M, Brooks SJ, Buitelaar J, van Daalen E, Fegert J, Findling RL, Fisman S, Greenhill LL, Huss M, Kusumakar V, Pine $\mathrm{D}$, Taylor E, Tyano S: International consensus statement on attention-deficit/hyperactivity disorder (ADHD) and disruptive behaviour disorders (DBDs): Clinical implications and treatment practice suggestions. Eur Neuropsychopharmacol 14:11-28, 2004.

Lam RW, Kennedy SH: Evidence-based strategies for achieving and sustaining full remission in depression: Focus on meta-analyses. Can J Psychiatry 49:17S-26S, 2004.

Mannuzza S, Klein RG, Bessler A, Malloy P, Hynes ME: Educational and occupational outcome of hyperactive boys grown up. J Am Acad Child Adolesc Psychiatry 36:1222-1227, 1997.

Michelson D, Allen AJ, Busner J, Casat C, Dunn D, Kratochvil C, Newcorn J, Sallee FR, Sangal RB, Saylor K, West S, Kelsey D,
Wernicke J, Trapp NJ, Harder D: Once-daily atomoxetine treatment for children and adolescents with attention deficit hyperactivity disorder: A randomized, placebo-controlled study. Am J Psychiatry 159:1896-1901, 2002.

Mohammadi MR, Akhondzadeh S: Pharmacotherapy of attentiondeficit/hyperactivity disorder: Nonstimulant medication approaches. Expert Rev Neurother 7:195-201, 2007.

MTA Cooperative Group: A 14-month randomized clinical trial of treatment strategies for attention-deficit/hyperactivity disorder. Arch Gen Psychiatry 56:1073-1086, 1999.

MTA Cooperative Group: National Institute of Mental Health Multimodal Treatment Study of ADHD follow-up: 24-month outcomes of treatment strategies for attention-deficit/hyperactivity disorder. Pediatrics 113:754-761, 2004.

Newcorn JH, Stein MA, Cooper KM: Dose-response characteristics in adolescents with attention-deficit/hyperactivity disorder treated with OROS methylpheniate in a 4-week, open-label, dose-titration study. J Child Adolesc Psychopharmacol 20:187-196, 2010.

Pelham WE, Gnagy EM, Burrows-Maclean L, Williams A, Fabiano GA, Morrisey SM, Chronis AM, Forehand GL, Nguyen CA, Hoffman MT, Lock TM, Fielbelkorn K, Coles EK, Panahon CJ, Steiner RL, Meichenbaum DL, Onyango AN, Morse GD: Once-aday Concerta methylphenidate versus three-times-daily methylphenidate in laboratory and natural settings. Pediatrics 107:E105, 2001.

Ramos-Quiroga JA, Casas M: Achieving remission as a routine goal of pharmacotherapy in attention-deficit hyperactivity disorder. CNS Drugs 25:17-36, 2011.

Remschmidt H: Global consensus on ADHD/HKD. Eur Child Adolesc Psychiatry 14:127-137, 2005.

Satterfield JH, Schell A: A prospective study of hyperactive boys with conduct problems and normal boys: Adolescent and adult criminality. J Am Acad Child Adolesc Psychiatry 36:1726-1735, 1997.

Schimmelmann BG, Mehler-Wex C, Lambert M, Schulze-zurWiesch C, Koch E, Flechtner HH, Gierow B, Maier J, Meyer E, Schulte-Markwort M: A prospective 12-week study of quetiapine in adolescents with schizophrenia spectrum disorders. J Child Adolesc Psychopharmacol 17:768-778, 2007.

Spencer T, Biederman J, Wilens T, Faraone S, Prince J, Gerard K, Doyle R, Parekh A, Kagan J, Bearman SK. Efficacy of a mixed amphetamine salts compound in adults with attention-deficit/ hyperactivity disorder. Arch Gen Psychiatry 58:775-782, 2001.

Steele M, Jensen PS, Quinn DM: Remission versus response as the goal of therapy in ADHD: A new standard for the field? Clin Ther 28:1892-1908, 2006a.

Steele M, Prinzo R, Binder C: Long-term effectiveness and safety of Concerta in children with ADHD: a six-month study. American Psychiatric Association. Annual Meeting, 2005a (Abstract NR 436).

Steele M, Prinzo R Binder C: The maintenance of effectiveness of Concerta in children with ADHD: An eight-month analysis. Washington (DC), American Psychiatric Association. Annual Meeting, 2005b (Abstract NR 434).

Steele M, Weiss M, Swanson J, Wang J, Prinzo RS, Binder CE: A randomized, controlled effectiveness trial of OROS-methylphenidate compared to usual care with immediate-release methylphenidate in attention deficit-hyperactivity disorder. Can J Clin Pharmacol 13:e50-62, 2006b.

Stein MA, Sarampote CS, Waldman ID, Robb AS, Conlon C, Pearl PL, Black DO, Seymour KE, Newcorn JH: A dose-response study of OROS methylphenidate in children with attention-deficit/hyperactivity disorder. Pediatrics 112:e404, 2003.

Swan J: SNAP-IV Scale. Irvine, CA: University of California, Irvine Child Development Center; 1995. 
Swanson JM, Kraemer HC, Hinshaw SP, Arnold LE, Conners CK, Abikoff HB, Clevenger W, Davies M, Elliott GR, Greenhill LL, Hechtman L, Hoza B, Jensen PS, March JS, Newcorn JH, Owens EB, Pelham WE, Schiller E, Severe JB, Simpson S, Vitiello B, Wells K, Wigal T, Wu M: Clinical relevance of the primary findings of the MTA: Success rates based on severity of ADHD and ODD symptoms at the end of treatment. J Am Acad Child Adolesc Psychiatry 40:168-179, 2001.

Swanson JM, Wigal SB, Wigal T, Sonuga-Barke E, Greenhill LL, Biederman J, Kollins S, Nguyen AS, DeCory HH, Hirshe Dirksen SJ, Hatch SJ: A comparison of once-daily extended-release methylphenidate formulations in children with attention deficit/hyperactivity disorder in the laboratory school (the COMACS Study). Pediatrics 113:e206-216, 2004.

Wang YC, Chong MY, Chou WJ, Yang JL: Prevalence of attention deficit hyperactivity disorder in primary school children in Taiwan. J Formos Med Assoc 92:133-138, 1993.

Weiss G, Hechtman L, Milroy T, Perlman T: Psychiatric status of hyperactive as adults: A controlled prospective 15-year follow-up of 63 hyperactive children. J Am Acad Child Psychiatry 24:211220, 1985.
Wigal SB, McGough JJ, McCracken JT, Biederman J, Spencer TJ, Posner KL, Wigal TL, Kollins SH, Clark TM, Mays DA, Zhang Y, Tulloch SJ: A laboratory school comparison of mixed amphetamine salts extended release (Adderall XR) and atomoxetine (Strattera) in school-aged children with attention deficit/hyperactivity disorder. J Atten Disord 9:275-289, 2005.

Wilens TE, Spencer TJ: The stimulants revisited. Child Adolesc Psychiat Clin N Am 9:573-603, 2000.

Yang P, Chung LC, Chen CS, Chen CC: Rapid improvement in academic grades following methylphenidate treatment in attention-deficit hyperactivity disorder. Psychiatry Clin Neurosci 58:37-41, 2004.

Address correspondence to:

Ying-Sheue Chen, M.D.

Department of Psychiatry

Taipei Veterans General Hospital No. 201, Sec. 2. Shih-Pai Road

Taipei

Taiwan, R.O.C.

E-mail: yschen@vghtpe.gov.tw 